\title{
Analysis of the small flying wings performances in the morphing concept
}

\author{
Vasile Prisacariu ${ }^{1, *}$, Ionică Cîrciu ${ }^{1}$, Doru Luculescu ${ }^{1}$, and Laurian Gherman ${ }^{2}$ \\ 1"Henri Coandă" Air Force Academy, Department of Aviation, Braşov, Romania \\ 2"Henri Coandă” Air Force Academy, Department of Air Defence, Braşov, Romania
}

\begin{abstract}
Using of the flying wing (the UAVs category) in various fields (civilian and military) determine interests sustained of the aerodynamic and trajectory optimizations. The article presents analysis of wing flying performance (in morphing concept) by studying optimizing the maneuvers control and wind tunnel tests.
\end{abstract}

\section{Theoretical aspects}

The geometry of the wing (dimensions, shape within the plane, profile, span thickness evolution, dihedral angle) is critical to the flight performance and characteristics of the aerial vehicle.

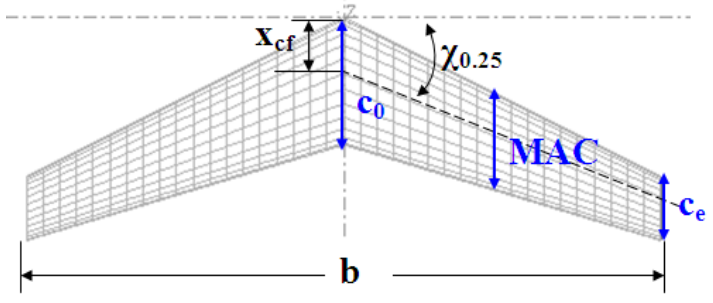

Fig. 1. Geometrical parameters of the swept wing.

If the line of the focal points does not coincide with axis $O y$, then the sweepback angle $\chi$ is revealed. If the Sweepback angle is reduced $\chi<15 \div 20^{0}$, the sweepback effect is reduced as well and the wing can be considered to be straight. If $\chi>30 \div 40^{0}$ the effect is significant and the wing is considered to be swept, [13]. The sweepback angle allows the adjustment of the centering of the aerial vector.

The positive wing sweep has a stabilizing dihedral effect. So, we have a wing with a sweepback angle $\chi$-measured on the line uniting $1 / 4$ of the chords, in the speed current $V$ and the positive angle of deflection $\beta$. Only the regular components create lift forces on the two semi-wings. These components are $V \cdot \cos (\chi-\beta)$, on the right semi-wing and $V \cdot \cos (\chi+\beta)$, on the left semi-wing. According to these speeds, a difference in lift appears $\left(\Delta F_{z}\right)$ :

\footnotetext{
* Corresponding author: aerosavelli73@yahoo.com
} 


$$
\Delta F_{z}=\frac{\rho \cdot S}{2} \cdot C_{z} \cdot V^{2} \cdot\left[\cos ^{2}(\chi-\beta)-\cos ^{2}(\chi+\beta)\right]
$$

Or, because $\beta$ is small, we approximate $\sin \beta=\beta, \cos \beta=1$, therefore:

$$
\Delta F_{z}=S \cdot \beta \cdot C_{z} \cdot \frac{\rho}{2} \cdot V^{2} \cdot \sin 2 \chi
$$

-the rolling moment is:

$$
L=-k \cdot \beta \cdot C_{z} \cdot \sin 2 \chi
$$

The neutral point coordinate is:

$$
x_{F}=\frac{c_{0}}{4}+\frac{2 b}{3 \pi} \cdot \operatorname{tg} \varphi_{0,25}
$$

If the ratio of trapezoids is $>0,375$ and

$$
x_{F}=\frac{c_{0}}{4}+\frac{b \cdot(1+2 \lambda)}{6 \cdot(1+\lambda)} \cdot \operatorname{tg} \varphi_{0,25}
$$

If the taper ratio is $<0,375$.

The aspect ratio influences the aerodynamic characteristics of the wing, the inertia moments and the weight of the structure is according to $[11,12,14,15]$.

$$
C_{z}=\frac{2 \pi \cdot \alpha \cdot \lambda}{\lambda+2}
$$

But for approximate calculation the following formula can be used:

$$
C_{z}^{\alpha}=\frac{5,73 \cdot \pi \cdot \lambda}{5,73+\pi \cdot \lambda}
$$

The global drag coefficient is expressed by:

$$
C_{x}=C_{x 0}+\frac{C_{z}^{2}}{\pi \cdot \lambda}
$$

And the induced angle:

$$
\alpha_{i}=\frac{C_{z}}{\pi \cdot e \cdot \lambda}(1+\delta)
$$

The coefficients for the sweepback angle of the wing are:

$$
C_{z}=C_{z n} \cdot \cos ^{2} \chi, C_{x}=C_{x n} \cdot \cos ^{3} \chi
$$

\section{Optimizing the maneuvers control}

The level of autonomous behavior of UAV increased recently, autonomy depending directly on the level of involvement human or resolution sensors. According to scientific references sense and avoid capability to UAVs can be optimized by making the leading 
characteristics and which contribute to adapt quickly to dynamic situations. Research has focused on numerical trajectory planning methods, such as direct (direct shooting, direct collocation, pseudospectral methods) and indirect methods, [5-7].

The maneuvers control along the trajectory can be optimized through a linear system, invariant to duration, and is associated through its reaction to stimulus. The reaction to stimulus is, almost always, dimensionally infinite. Since in the case of the stable systems the stimulus exponentially tends to 0 , we can assume that it can be simplified. It can be neglected for a period of quantization, in comparison to the constants of the system, which cannot. A significant number of parameters are necessary for indicating the simplified signal. Therefore, we have an example of the finite response to stimulus $[1,10]$.

This example can be shown by means of the following relations:

$$
\begin{gathered}
y(p)=x_{1} \cdot n \cdot(t-1)+x \cdot n \cdot(t-2)+\ldots+x_{p} \cdot n \cdot(t-p) \\
y(p)=\varphi^{T} \cdot(p-1) \cdot \phi
\end{gathered}
$$

Where:

$$
\phi=\left[x_{1}, x_{2} \ldots x_{p}\right]^{T}
$$

With

$$
\varphi^{T} \cdot(p-1)=[n \cdot(t-1) \cdot n \cdot(t-2) \cdot \ldots \cdot n \cdot(t-p)]^{T}
$$

The structure can be viewed as a system with entries $\mathrm{n}$ and $\mathrm{y}$ and exit $\phi$. Double correction can be noticed: the first correction through the proper correction loop itself and the second one by a supplementary comparison to a preset program (see fig. 2).

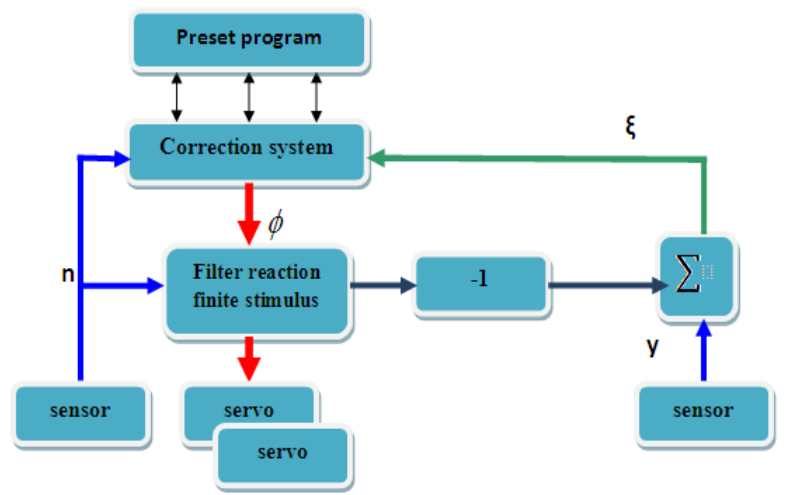

Fig. 2. Simplified block-diagram of a recursive system.

In the correction loop we can introduce constant initial values of the flight altitude (altitude sensor) and/or of the turning speed for the angle of inclination while in the preset program we can set these values before the mission according to the mass of the UAV. The proposed system highlights the way a flight stabilizer works and can influence the maneuverability of the UAV along the trajectory depending on the type of mission.

Figure 3 show the two situations, with and without longitudinal stabilization (2D) during a 10 second turning.

For example: the rolling is set on $25^{\circ}$ and the measured rolling is $15^{\circ}$; an error will immediately be displayed at the rolling control and the ailerons will respond until the value 
of $25^{0}$ with 0 error will be reported on the rolling channel. Throughout the rolling, the nose of the UAV will be descending while the pitch controller will control the pitch until 0 errors is present.

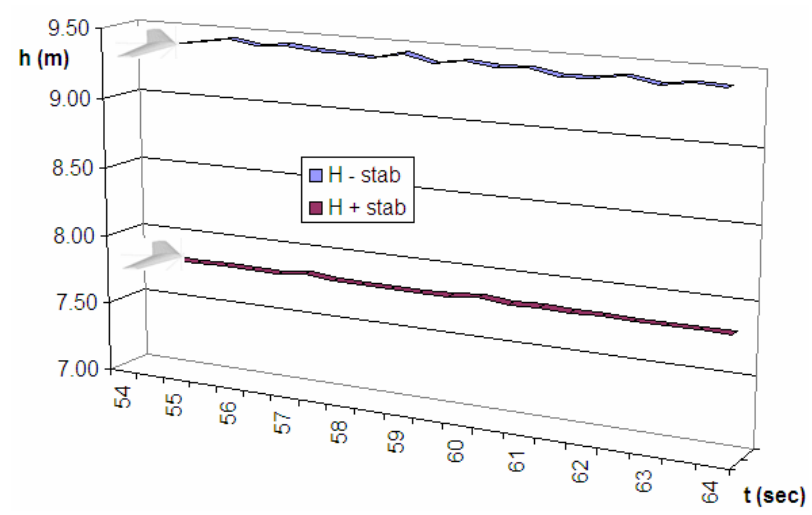

Fig. 3. Longitudinal stability.

\section{Experimental research with tunnel tests}

The approach used in this section aims at a comparative analysis of the results taken from tests in the wind tunnel by the two configurations (classical and the morphing) with results obtained from CFD numerical analysis.

\subsection{Characteristics of the aerial vector proposed for the tunnel tests}

The tests in the aerodynamic tunnel were performed in the subsonic tunnel of INCAS, Bucharest, in order to provide data for investigating the benefits of the morphing concept [2]. The model used for the experimental testing had been made of materials available on the market. The lifting surface is of expanded polystyrene and covered with a thermo retractable foil. The configuration is double trapezoidal (see figure 4) having the geometry in Figure 4.

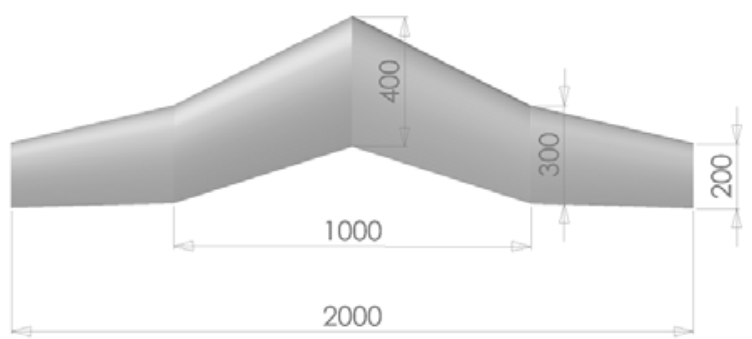

Fig. 4. Experimental model.

The wings subject to tunnel tests have a Clark $\mathrm{Y}$ airfoil and do not display any constructive torsion at plane edges but there are pairs of winglets mounted on them for stabilization. The changes in angles of torsion of the wings from the basic configurations are made by use of two standard Futaba S3003 servomechanisms (see table 2). 
Table 2. Futaba S 3003 features.

\begin{tabular}{|c|c|c|c|}
\hline Signal & analogue & Drive limit & $\mathbf{3 . 2} \mathbf{~ K g} \cdot \mathbf{c m}$ at $4.8 \mathrm{~V}$ \\
\hline Execution speed & $0.23 \mathrm{sec} / 60^{\circ}$ at $4.8 \mathrm{~V}$ & Weight & $38 \mathrm{~g}$ \\
\hline
\end{tabular}

They are activated through the command and control system [3], both for the longitudinal channel and lateral channel. The basic configurations of the flying wings have been fitted with identical pairs of winglets, the classical wing being equipped with articulated elevons activated by servomechanisms while the morphing wing is activated by a torsion bar type system the tips ribs being activated by servomechanisms (see figure 5).

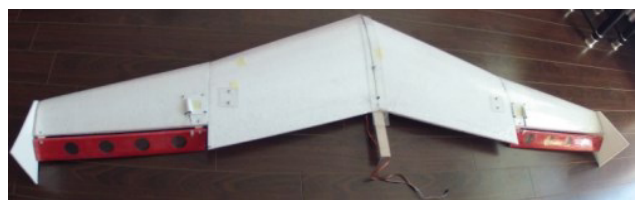

Classical flying wing

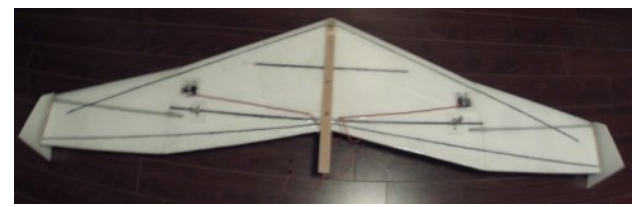

Morphing flying wing

Fig. 5. Experimental models.

\subsection{Description of the subsonic aerodynamic tunnel where the tests were performed}

The aerodynamic tunnel used is closed-circuit, subsonic with continuous flow generated by a direct current electric motor $(3.5 \mathrm{~m}$ per diameter) and a $20 \mathrm{KW}$ electro-ventilator for separate cooling. It is equipped with an external measurement balance (six components forces and moments) with precision of $1 / 25000$ and a data acquisition system with LABVIEW software.

The acquisition system is controlled by the computer and based on a National Instruments base with eight PXI 1042 slots [4] with synchronization at $10 \mathrm{MHz}$ for the existing models. Table 3 shows the main characteristics of the tunnel [2].

Table 3. Characteristics of the subsonic wind tunnel.

\begin{tabular}{|c|c|c|c|}
\hline Testing room dimensions & $\mathbf{4} \times \mathbf{2} \times \mathbf{2 . 5} \mathbf{~ m}$ & K contraction ratio & $\mathbf{1 0}$ \\
\hline Speed & $7 \div 110 \mathrm{~m} / \mathrm{s}$ & Angle of turning & $-140^{0} \div 216^{0}$ \\
\hline Reynolds & $1 \times 10^{6}$ & Angle of incidence & $-45^{0} \div 45^{0}$ \\
\hline Turbulence factor & 1,11 & Fan motor & $1200 \mathrm{kw}$ \\
\hline
\end{tabular}

The experimental models were mounted on three points, leaving the rear assembly mobile for making possible the modification of the angle of incidence during the tests (see figure 6).

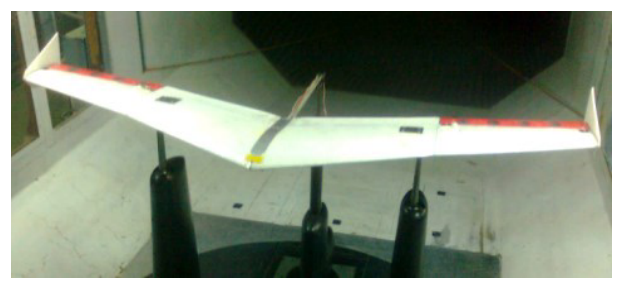

Classical flying wing

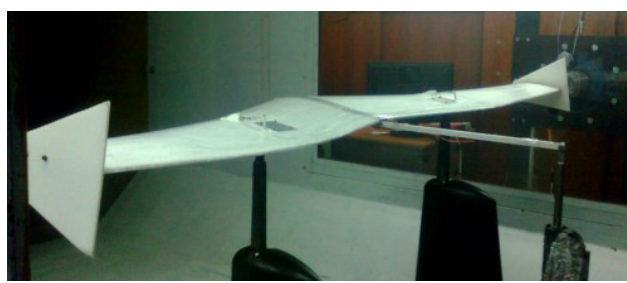

Morphing flying wing

Fig. 6. Testing room of the subsonic tunnel. 
External balance calibration and the estimations were made before the wind tests. The tests covered a range of $-4^{0}$ to $10^{0}$ for a speed of $10 \mathrm{~m} / \mathrm{s}$, the experimental models were controlled by means of a command and control system on $2.4 \mathrm{GHz}$ and two channels [3] and the calibration of the control surfaces (classical/morphing elevons) was performed using a digital inclinometer with an error of $0.1^{0}$.

The experimental models (classical and morphing) were tested under the same conditions, without any activation of the control surfaces, for the comparative analysis of the physical measurement data collected, [9].

\subsection{Results and discussions}

The following conventions are applied when presenting results: the moments are shown in axes system (axis Ox opposite to the flight direction, axis $\mathrm{O}_{\mathrm{z}}$ upwards, axis $\mathrm{O}_{\mathrm{y}}$ to the right) (see figure 7); the mean aerodynamic chord (MAC) was the reference length for the diving moment. The moments that have been measured are referenced to the centre of gravity (CG).

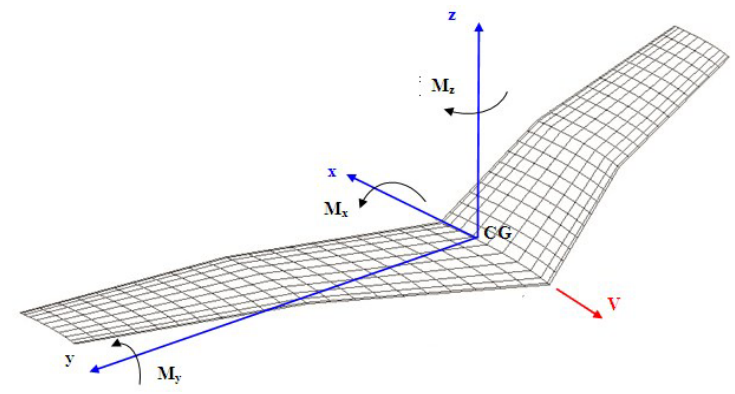

Fig. 7. Reference system.

The data collected during the tunnel tests provided values for the following: the lift force $\left(F_{z}\right)$, the force of resistance to movement $\left(F_{x}\right)$, the lateral force $\left(F_{y}\right)$, the pitch moment $\left(\mathrm{M}_{\mathrm{y}}\right)$, the rolling moment $\left(\mathrm{M}_{\mathrm{x}}\right)$ and the gyration moment $\left(\mathrm{M}_{\mathrm{z}}\right)$. The data collection system provided unprocessed data which needs to be corrected according to instructions for use of the aerodynamic balance. After data processing we obtain the aerodynamic parameters in figure 8 .

The variation of the aerodynamic coefficients according to CFD analysis with ANSYS provides a numerical reference for the comparative analysis of the tunnel tests (see figure 8). Compared to the classical wing, in the case of the morphing wing, an increase of coefficients $C_{z}, C_{x}$ and $C_{m}$ on a range of $0^{0}-8^{0}$ of the incidence angle can be noticed.
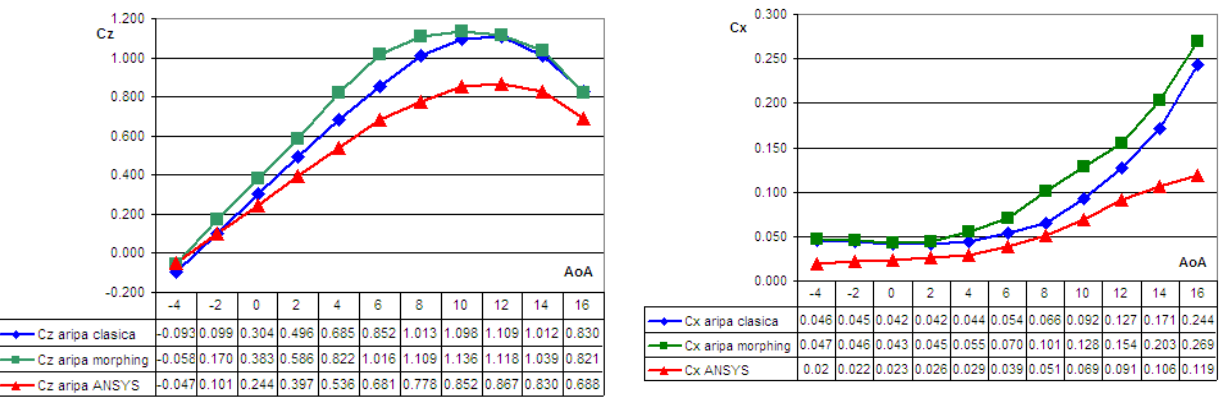

Fig. 8. Comparative curves of the polar diagrams $\left(C_{z^{-}}-A o A, C_{x^{-}}-A o A\right)$. 
Figure 8 shows a good behavior (for $\mathrm{V}=10 \mathrm{~m} / \mathrm{s}$ and $\mathrm{Re}=2.15 \times 10^{5}$ ) in the angles of incidence stall and post-stall aerodynamic performance is not significantly affected.

\section{Conclusions and future research considerations}

The analysis of both aerodynamic and flight mechanics aspects of the morphing concept flying wing aims at providing an overall idea regarding the aerodynamic performance of these small aerial vehicles in order to better understand the compromise between aerodynamic efficiency and superior maneuvers characteristics in the context of increased power efficiency.

The main advantages of the flying wing are increased aerodynamic performances (reduced weight, increased maneuverability). The literature in the field rarely mentions the swept flying wing of the UAS type in terms of aerodynamic performance depending on maneuvers characteristics.

The step by step analysis as part of a simplified theoretical approach, the CFD-3D simulations and the aerodynamic tunnel tests offer the opportunity for improving existing options regarding the projection of the aerial vector.

The comparison of CFD-3D simulation results to the aerodynamic tunnel test ones ensures the accuracy of the aerodynamic performances as well as the formulation of conclusions related to important aspects of flight mechanics.

The applications proposed are relevant to the field of miniature UAVs research in what regards the two maneuvers described (turning and spiral), which are typical for this type of aerial vehicles.

Our contribution is a new, simple, and intuitive way of connecting aerodynamic performances to flight mechanics aspects regarding the two maneuvers. It offers good accuracy results. The examples for the turning and the spiral as simple maneuvers are also relevant to the development of new tactical capabilities of small UAVs through improving the performance itself. Moreover, the applications could be helpful in the development of new tactical capabilities of UAVs related to the global performance indicator in a synergic way.

The authors wish to thank "Transylvania" University and "Henri Coandă" Air Force Academy of Braşov and INCAS Bucureşti for supporting the research necessary for writing this article. This work is supported by the Executive Agency for Higher Education, Research, Development and Innovation Funding (UEFISCDI) under MASIM project (PN-II-PT-PCCA-2013-4-1349).

\section{References}

1. K. Nonami, M. Kartidjo, and others, Autonomus control systems and vehicles. Inteligent Unmanned Systems, (Springer Series, 65, 2013)

2. M.V. Pricop, C. Stoica, C. Nae şi alţii, INCAS Bulletin, 4, 67 (2012)

3. Futaba Corporation, Instruction manual for Futaba 6EXAP 6-channel, PCM/PPM (FM) selectable, Radio control system for aircraft, 2005, 24p, available at http://www.manualslib.com/manual/378276/Futaba-6exap.html, accessed on 19.09.2014

4. National Instruments, User Manual 6023E/6024E/6025E, Multifunction I/O Devices for PCI, PXI, CompactPCI, and PCMCIA Bus Computers, Part Number 322072C-01, Austin Texas

5. Betts, J.T., Journal of Guidance, Control, and Dynamics, 121, 193 (1998)

6. Yakimenko, O.A., Y. Xu, and G. Basset, Collection of Technical Papers - AIAA Guidance, 2008, Navigation, and Control Conference, 1, 1 (2008)

7. G.T. Huntington, D.A. Benson, and A.V. Rao, Collection of Technical Papers - AIAA Guidance, Navigation, and Control Conference, 1, 840 (2007) 
8. B. Geiger, Unmanned Aerial Vehicle trajectory planning with direct methods, The Pennsylvania State University, available at https://etda.libraries.psu.edu/files/final_submissions/767

9. V. Prisacariu, Managementul integrării soluţillor tehnice inovative la sisteme aeriene robotizate, teză de doctorat, (Universitatea Transilvania Braşov, 2014, available at webbut.unitbv.ro/teze/rezumate/2014/rom/PrisacariuVasile.pdf)

10. I. Cîrciu, V. Prisacariu, Review of the Air Force Academy, Braşov, Romania, 1, 13 (2013)

11. D.P. Raymer, Aircraft design: A conceptual approach (4th edition), AIAA Education series, California-USA,840 (2006)

12. J.D. Anderson jr., Aircraft performance and design (McGraw-Hill Book-Co Singapore, 580, 1999)

13. N.V. Constantinescu, S. Găletuşe, Mecanica fluidelor şi elemente de aerodinamică (Editura Didactică şi Pedagogică, Bucureşti, 1983)

14. V. Prisacariu, M. Boşcoianu, I. Cîrciu, C-G. Rău, Advanced Materials Research, 463-464, 1564 (2012)

15. V. Prisacariu, M. Boşcoianu, I. Cîrciu, Applied Mechanics And Materials, 332, 44 (2013) 